\title{
Analysis of New Energy Consumptive Capacity Based on the Constraints of Voltage Stability
}

\author{
Hualing HAN ${ }^{*}, 1, \mathbf{a}$, Mengmeng SUN ${ }^{1, \mathbf{b}}$, Ning CHEN ${ }^{1, \mathbf{c}}$, Ruoying YU ${ }^{1, \mathbf{b}}$ \\ ${ }^{1}$ China Electric Power Research Institute, Nanjing, Jiangsu Province, China \\ aemail:hanhualing@epri.sgcc.com.cn
}

\begin{abstract}
Keywords: New Energy ; Consumptive Capacity; Voltage Stability.
Abstract: Three main factors of constraining the wind power consumptive capacity of the northern Hebei Province grid are capacity of main transformer, transmission channels and voltage stability limit of regional power grid. This paper does research on the new energy consumptive capacity limit considering the static voltage stability.
\end{abstract}

\section{Introduction}

The development of wind power in China is mainly concentrated in the "Three North" region (Northeast China, Northwest China and North China). Because of the reasons of the asynchronous between the wind power construction and power grid construction, low load of regional power grid, few fast-adjustable power plant and etc..., the consumptive capacity of wind power is weak which lead to the difficulty of wind power connecting to grid and the phenomenon of the "Abandoning wind" is outstanding. In order to promote the sustainable development of new energy sources, it is meaningful to do research on the consumptive capacity of new energy sources such as the wind power, photovoltaic and any other new energy source and to propose the operation strategy of new energy scheduling.

According to the actual research, there are three main factors of constraining the wind power consumptive capacity of the northern Hebei Province grid: capacity of main transformer, transmission channels and voltage stability limit of regional power grid. This paper mainly does research on the new energy consumptive capacity limit in North China considering the static voltage stability.

\section{Analysis of new energy consumptive capacity limit considering the static voltage stability}

\section{A. Analysis of new energy consumptive capacity limit in North Hebei}

Considering thetransmission capacity constraints, the adjusting peaking power constraints and static voltage stability to analyze the consumptive capacity of the wind power. It is feasible to improve the consumptive capacity by changing the connecting point of wind power 2.3 million $\mathrm{kW}$ (3.8 million $\mathrm{kW}$ in total) of Guyuan Region to Bailong and Yiyuan Region. Running under the grid structure in northern Hebei China, the consumptive capacity of the wind power in Zhangjiakou Region increases to $5412 \mathrm{MW}$, whic the proportion consumptive capacity of the wind power is $75 \%$. 


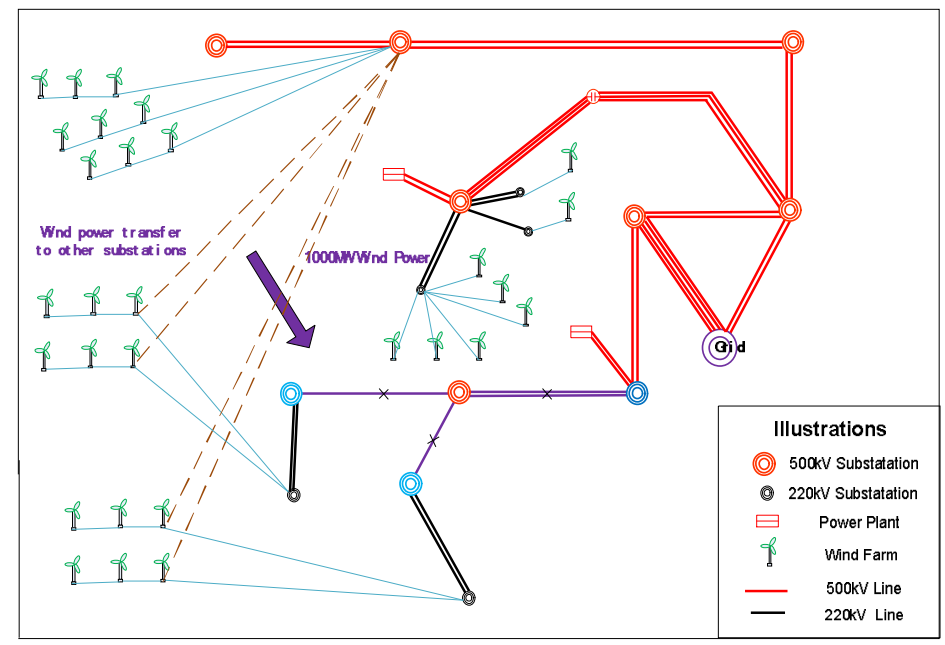

Fig.1 "Three stand four-wire" promoting the wind power consumption

\section{B. Flow Analysis in basic operation mode}

This section will calculate the flow in North Hebei grid China after connecting the wind power which have about 5.5 million $\mathrm{kW}$ capacity.

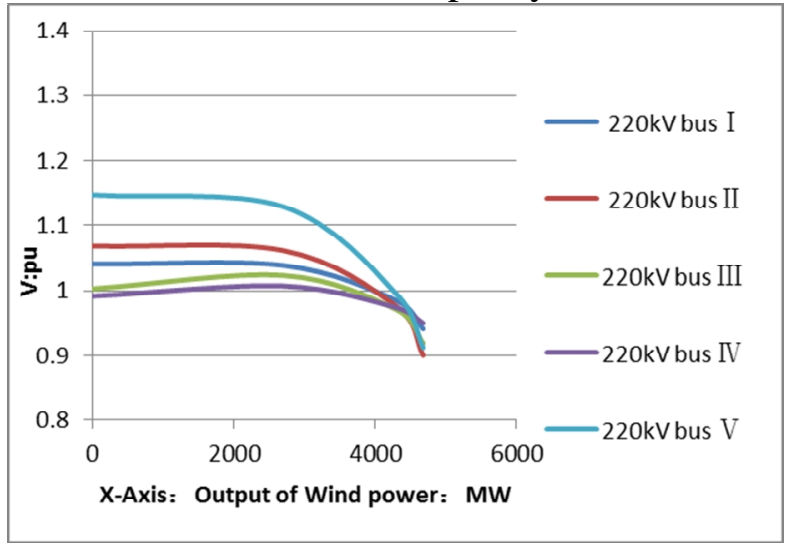

Fig. 2 Bus voltage curve

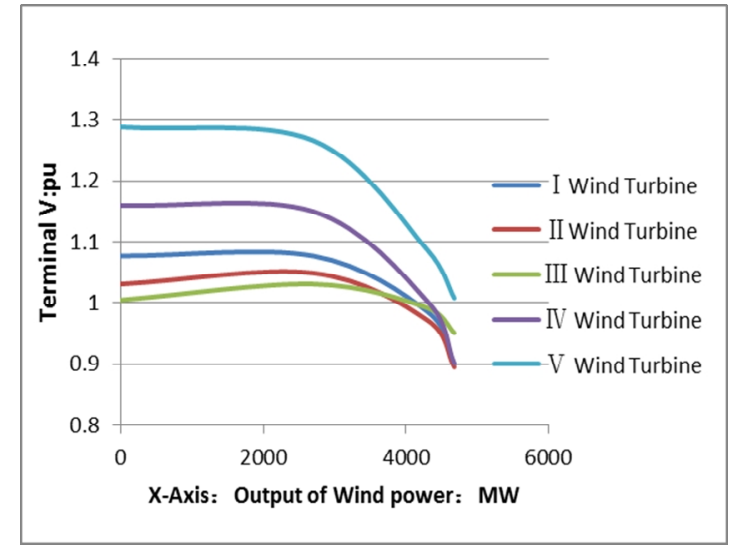

Fig.3 Generator power angle curve

Figure 2-3 is the PV curve of part nodes of the system. When the output of the wind power increases, the grid voltage will gradually reduce. Reactive power compensation device of the wind farm can regulate the voltage level of the regional power grid, But static voltage stability of the grid will continue to decrease with the increasing power of the wind farm. When more than 4679MW of wind power connecting to Zhangjiakou Region, The grid voltage instability will occur.

The wind power capacity of Zhangjiakou region is 5412MW, the initial consumptive capacity is $4078 \mathrm{MW}$. According to the flow calculation, we know that the consumptive limit of wind power of Zhangjiakou area is $4679 \mathrm{MW}$ considering static voltage stability constraints shown in Tab.1.

Tab.1 wind power consumptive situation in maximum operating mode

\begin{tabular}{|c|c|c|c|c|c|}
\hline Area Code & $\begin{array}{c}\text { The } \\
\text { accessing } \\
\text { capacity } \\
\text { MW })\end{array}$ & $\begin{array}{c}\text { The initial } \\
\text { operational } \\
\text { status } \\
(\%)\end{array}$ & $\begin{array}{c}\text { The initial } \\
\text { accessing } \\
\text { capacity }( \\
\text { MW })\end{array}$ & $\begin{array}{c}\text { consumptive } \\
\text { limit } \\
(\%)\end{array}$ & $\begin{array}{c}\text { static } \\
\text { voltage } \\
\text { limit } \\
(\mathrm{MW})\end{array}$ \\
\hline FA & 918.5 & 0.7 & 642.95 & 0.95 & 872.575 \\
\hline FB & 806.3 & 0.7 & 564.41 & 0.76 & 612.788 \\
\hline FC & 792.55 & 0.7 & 554.785 & 0.9 & 713.295 \\
\hline FD & 809 & 0.8 & 647.2 & 0.9 & 728.1 \\
\hline FG & 700.5 & 0.8 & 560.4 & 0.9 & 630.45 \\
\hline FH & 1385.5 & 0.8 & 1108.4 & 0.81 & 1122.255 \\
\hline Total & 5412.35 & & 4078.145 & & 4679.463 \\
\hline
\end{tabular}




\section{Strategy Research by of improving consumptive capacity of new energy}

\section{A. Research of improving consumptive capacity of new energy in reactive power adjusting strategy}

Fig.4 show the mothod of improving consumptive capacity of new energy in reactive power adjusting strategy in Zhangbei area. In maximum operating mode in 2015 in northern Hebei, according to different accessing capacity of wind power, do research on the flow calculation analysis in the current operating mode. Constraints to the voltage of key nodes, to calculate the reactive power egulation limits according to the output power of the wind power. In the case of reactive power egulation can not meet the requirements, to do research on reactive power configuration in the system side.

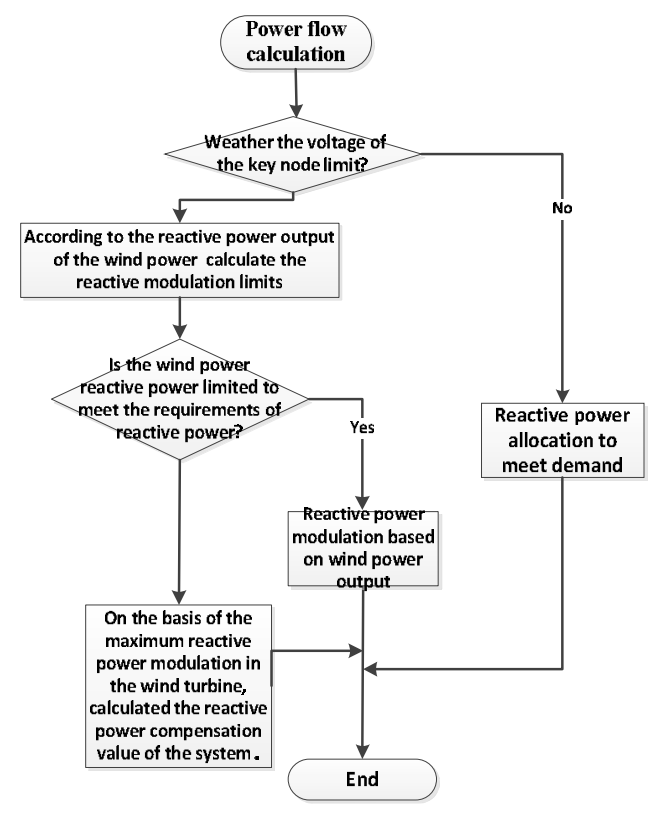

Fig.4 Reactive power adjusting strategy

\section{B. Influence of grid voltage according to reactive power regulation capability of wind farm}

This section mainly analyze the influence of grid voltage accroding to different control strategies of actual wind farms. Control strategies are the Constant Voltage Control and the Constant power factor Control.

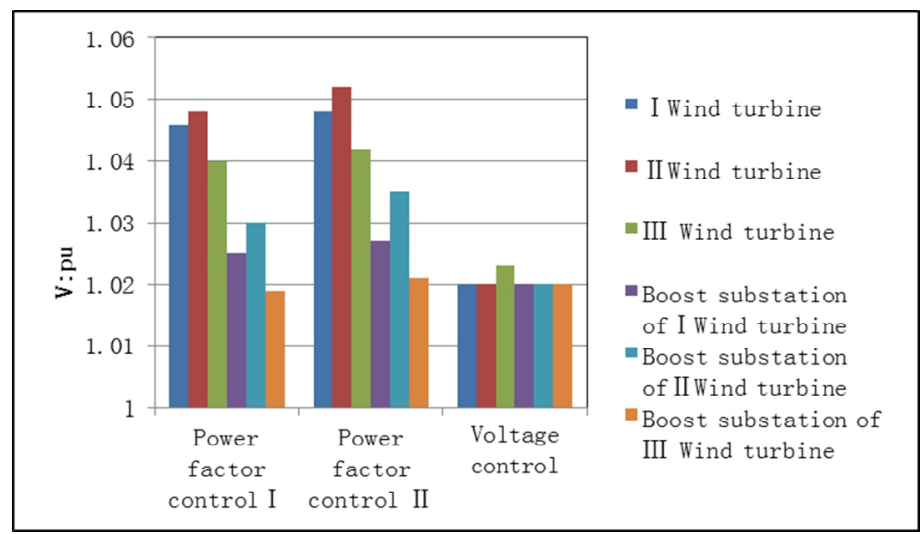

Fig.5 Bus voltage curve

Control I mode indicates that the control objectives is that the export power factor of the wind farm is 1; Control II mode indicates that the control objectives is that the power factor of point of interconnection is 1 ; Voltage control indicates that the control objectives is the voltage of point of interconnection is $1.02 \mathrm{pu}$. 


\section{Transient Stability Checking in the case of new energy accessing}

After determining the configuration of reactive power compensation and the consumptive capability of wind power according to static stability limit, it need to transient check the result.

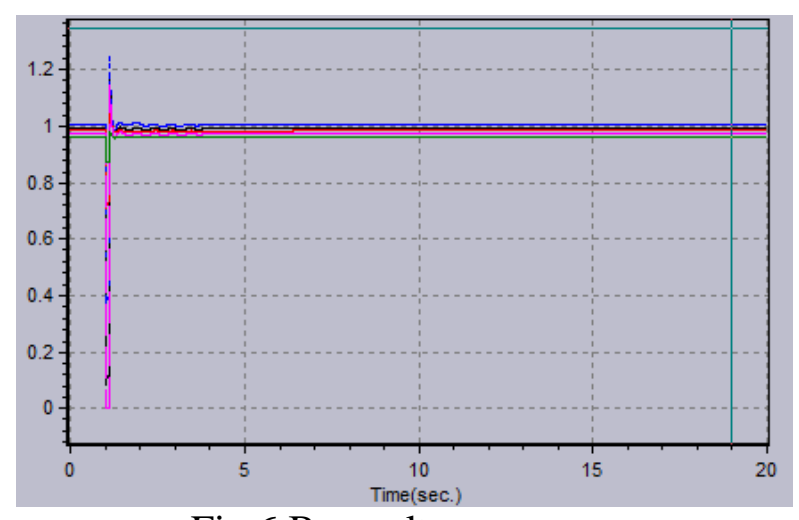

Fig.6 Bus voltage curve

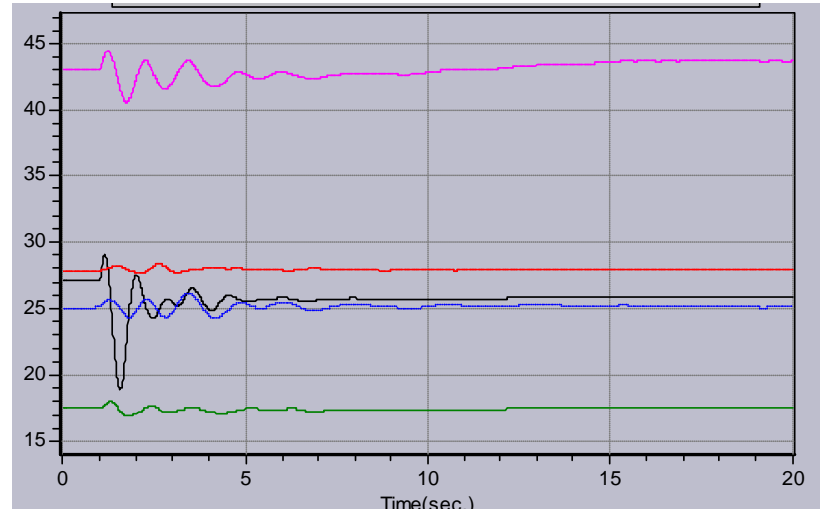

Fig.7 Generator power angle curve

After connecting the wind farm, when three phase short-circuit fault occurs in $220 \mathrm{kV}$ line at $1 \mathrm{~s}$ and clearing at 1.1s, the curve of relevant variables is shown in Fig 6-7.

Each wind turbine in the power grid can restore stability after power-angle swing, The frequency can restore stability and the bus voltage can restore to normal.

\section{Conclusions and suggestion}

The main conclusions are as follows:

( i ) To improve the new energy consumptive capacity in northern Hebei, it is need to increase the power grid construction, transmission channel and enhanced transmission capacity.

( ii ) To increase reactive-voltage control method to improve the local grid voltage stability, will help to improve the consumptive capacity of wind power in regional power grid. The most direct and effective way to enhance the consumptive capacity of wind power is increasing the power grid construction. Increasing reactive-voltage control methods is the auxiliary way.

( iii ) It is configured with 857 Mvar of reactive power compensation in Zhangjiakou region, by full using reactive power regulation capability of wind turbine and using reasonable reactive power control modes, it is feasible to effective static voltage stability and improve the consumptive capacity of wind power in regional power grid.

\section{Acknowledgment}

The research achievements of this paper is derived from the sponsorship of China State Grid Corp technology project [NY71-13-043].

\section{References}

[1] Long B,Ajjarapu V. The sparse formulation of ISPS and its application to voltage stability margin sensitivity and estimation[J]. Power Systems, IEEE Transactionson, 1999,14(3): 944-951

[2] Meegahapola L,Flynn D,Littler T. Transient stability analysis of a power system with high wind penetration[C]//Universities Power Engineering Conference,2008. UPEC 43rd International. IEEE, 2008: 1-5

[3] Marcus VAN,Pec as J A, Ha ns H Z. Influence of the variable-speed wind generators in transient stability margin of the conventional generators integrated in electrical grids [J]. IEEE Trans on Energy Conversion 2004,19(4):692-701 
